\title{
Modulation of murine macrophages phagocytic activity by polysaccharide extract from Chenopodium bonus-henricus
}

\author{
MARIUS ZĂHAN, ILEANA MICLEA, ADRIANA CRISTE, VASILE MICLEA
}

Department of Life Sciences and Biotechnology, University of Agricultural Sciences and Veterinary Medicine, Cluj-Napoca, Romania

\begin{abstract}
Chenopodium bonus-henricus (popularly known as Good King Henry or Perennial Goosefoot) is a spontaneous plant used for its cicatrisation, anti-arthritis and anti-cough properties and also for antimicrobial, antifungal, vermifuge, anti-inflammatory, diuretic and immunomodulating effects. Despite these, it is not recognized as an important medicinal plant in the international pharmacopeias, probably because of the few existent researches. In this context our study was made to assess the effect of the polysaccharides extract of Chenopodium bonus-henricus herb on cellular immunity. Murine peritoneal macrophages were incubated with 20,30, 60 and $80 \mu \mathrm{g} / \mathrm{ml}$ of the extract. In order to evaluate the phagocytosis response, sheep red blood cells were co-cultivated with the treated macrophages. Results showed that polysaccharide extracts increase the phagocytic activity of murine macrophage depending on the concentration. The highest values of the phagocytic index and mean phagocytosis were obtained at $30 \mu \mathrm{g} / \mathrm{ml}$ concentration. Considering mice the main mammalian model organism for studying certain human diseases, Chenopodium bonus-henricus might have clinical applications due to its immunomodulatory properties.
\end{abstract}

Key words: polysaccharide extract, Chenopodium bonus-henricus, murine, phagocytic activity.

(Centr Eur J Immunol 2013; 38 (2): 183-186)

\section{Introduction}

The genus Chenopodium includes more than 200 species spread in Europe, Asia and both North and South America. Although many of these possess therapeutic and edible properties, the medicinal uses of Chenopodium are not widely known [1]. Chenopodium bonus henricus L., named the shepherd's spinach (in Romania), or Good King Henry, Perennial Goosefoot and God's herb (in other countries), is a spontaneous, nitrofil plant. Its medicinal properties and nutritional qualities have been known to people since ancient times [2]. This plant is used in folk medicine for cicatrisation, anti-arthritis and anti-cough properties and also for antimicrobial, antifungal, vermifuge, anti-inflammatory, diuretic and immunomodulating effects. Its nutritional value is due to the high content of proteins and iron, considered to be a good food plant.

According to Kokanova-Nedialkova et al. [1], the genus Chenopodium includes 379 compounds of diverse chemi- cal nature: minerals, primary metabolites - carbohydrates, amino acids, nonpolar constituents, proteins, aromatic cytokinins, hormones and secondary metabolites flavonoids, saponins, terpenes, sterols, alkaloids and vitamins. In the case of bonus henricus, there were found some active principles such as polyphenol, saponins, tannins, ecdysteroids, polysaccharides [3] and vitamin C [4].

There are a lot of researches that show immunomodulatory effects of certain vegetal compounds, most of them including polysaccharides and carotenoid pigments. Nonspecific immunomodulatory activity of aqueous and hydroalcoholic extracts of under-ground parts of Rhodiola quadrifida had been demonstrated in pigs, rats and mice in in vitro and in vivo experimental models [5, 6]. Concerning immunopharmacology, carbohydrate macromolecules represent nonspecific immunostimulatory or para immunity inducers [7]. Polysaccharide fractions (with molecular weights between 25000 and 50000) isolated from the water

Correspondence: Marius Zăhan, University of Agricultural Sciences and Veterinary Medicine, Department of Life Sciences and Biotechnology, 3-5 Mănăştur Street, 400372, Cluj-Napoca, Romania, tel. +40-264-596384, fax +40-264-593792, e-mail: mzahan @usamvcluj.ro 
or water-alkaline extract of Echinacea, Eupatorium, Chamomilla, Calendula, Baptisia, Achyrocline, Arnica, Sabal and Eleutherococcus proved to have good immunomodulatory effects in the carbon clearance test [8]. Pharmacological studies have shown that polysaccharide extracts and saponins obtained from Chenopodium bonushenricus are not toxic and are efficient in treating high blood-lipid content [9].

The aim of this experiment was to determine the effect of different concentrations of the polysaccharide extract from Chenopodium bonus-henricus on the phagocytic activity of peritoneal murine macrophages.

\section{Material and methods}

The chemicals were purchased from Sigma Chemical Company (St. Louis, MO, USA) and the antibiotics from Antibiotice (Iaşi, Romania). Polysaccharides were isolated from Chenopodium bonus-henricus herb using hot water extraction, ethanol and acetic acid precipitation and then sterilized by microfiltration according to the previously described method by Hanganu et al. [10]. Experiments were performed using five male Swiss white mice and were approved by the local Ethical Committee (No. 14618/27.09.2012). Resident peritoneal macrophage cultures were obtained following a previously reported method [11]. The mononuclear cell fractions were washed twice in Dulbecco phosphate buffer solution pH 7.4 (DPBS - Sigma, D1408) and collected in RPMI 1640 medium (Sigma, R8758) supplemented with 5\% heat-inactivated fetal calf serum (FCS - Sigma, F0392), 100 $\mathrm{IU} / \mathrm{ml}$ penicillin $\mathrm{G}$ (Antibiotice) and $100 \mu \mathrm{g} / \mathrm{ml}$ streptomycin sulphate (Antibiotice). Cell density and viability have been assessed by the trypan-blue exclusion test (viability min 95\%) and consequently cell suspension was adjusted to $3 \times 10^{6}$

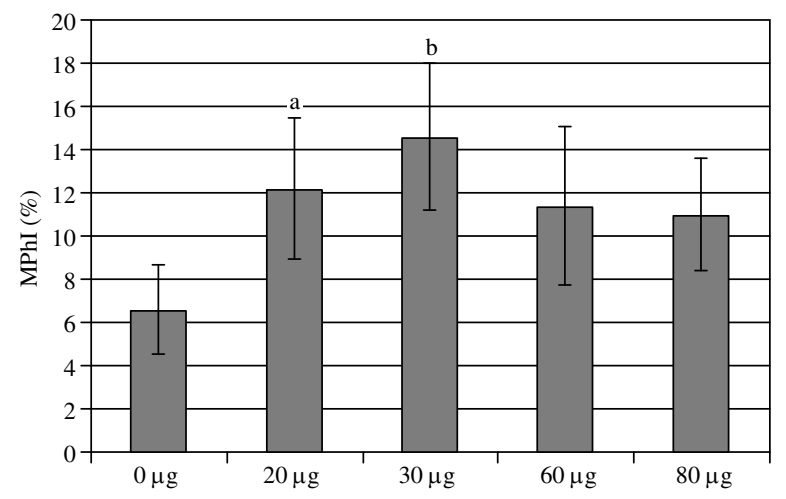

Fig. 1. Effects of polysaccharide concentrations of Chenopodium bonus-henricus herbal extract on phagocytic index $(\mathrm{MPhI} \%)$. The values between the control group and labeled columns differ significantly: a) $p<0.05$; b) $p<0.01$. Statistical analysis was performed by one-way ANOVA and Dunnett Multiple Comparison Test macrophages $/ \mathrm{ml}$. One milliliter of this cell suspension was dispensed into each of the four compartments of a Petri dish containing one sterile glass coverslip. The culture dishes were incubated at $37^{\circ} \mathrm{C}$ in a humidified incubator in the presence of $5 \% \mathrm{CO}_{2}$. After $24 \mathrm{~h}$ of incubation, the coverslips were washed with DPBS to remove non-adherent cells. For the next $48 \mathrm{~h}$ washed coverslips were transferred to new Petri dishes containing fresh growth medium. After that, the macrophage cultures were exposed (in duplicates) to DMSO (control group, final concentration $0.03 \% \mathrm{v} / \mathrm{v}$ ) (Sigma, D2650) and to experimental trials of polysaccharide extracts in 20,30, 60 and $80 \mu \mathrm{g} / \mathrm{ml}$ concentrations for $2 \mathrm{~h}$ incubation.

Phagocytic activity of peripheral macrophage cells for sheep red blood cells (SRBC) was determined as previously reported [12]. Briefly, freshly collected SRBC were washed three times in sterile phosphate buffer saline $\mathrm{pH} 7.2$ (PBS, Sigma, P5493) and 5\% SRBC suspension was extemporaneously prepared in RPMI 1640 . The culture medium was removed and $1.0 \mathrm{ml}$ of the $5 \%$ SRBC suspension was added to each coverslip sample. After $1 \mathrm{~h}$ of incubation, the coverslips were washed to remove free SRBC, then fixed in methanol for $10 \mathrm{~min}$, stained with May-GrünwaldGiemsa and mounted on clean glass slides. Two hundred macrophages per coverslip were scored microscopically at $100 \times$ magnification. The following parameters were defined: phagocytic index (MPhI\%) as the percent of phagocytic macrophages and the mean phagocytosis (MP) as the number of SRBC per macrophage. The experiment has been repeated five times.

The results were statistically analyzed using one-way ANOVA. When ANOVA presented considerable differences, we used Dunnett Multiple Comparisons Test. All statistic analyses were made using GraphPad InStat.

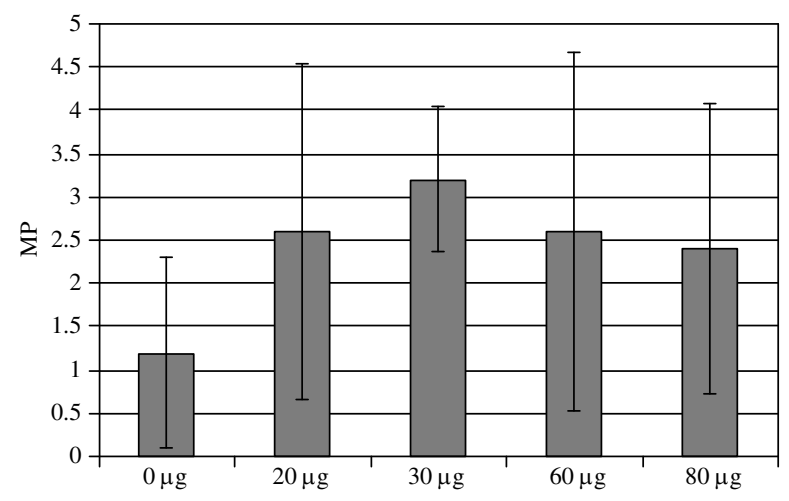

Fig. 2. Effects of polysaccharide concentrations of Chenopodium bonus-henricus herbal extract on mean phagocytosis (MP). The values between control and experimental groups did not differ significantly by one-way ANOVA analysis 


\section{Results}

The herbal extracts of Chenopodium bonus-henricus have shown a stimulatory effect on phagocytic capacity of mouse macrophages (Fig. 1). In all experimental trials with different concentrations of polysaccharides, SRBC uptake increased $(12.3 \pm 3.29 \%)$ in comparison with the control group $(6.6 \pm 2.07 \%)$. MPhI\% was significantly higher at $20 \mu \mathrm{g} / \mathrm{ml}$ $(12.2 \pm 3.27 \% ; p<0.05)$ and $30 \mu \mathrm{g} / \mathrm{ml}(14.6 \pm 3.36 \%$; $p<0.01)$ in comparison with the control group. The same distribution of the results was observed in the case of MP (Fig. 2), with a lower value in the control group $(1.2 \pm 1.09 \%)$ and a higher value in the $30 \mu \mathrm{g} / \mathrm{ml}$ group $(3.2 \pm 0.83 \%)$.

The immunomodulatory effect of polysaccharides from Chenopodium bonus-henricus herb was also tested on adult hens by Hanganu et al. [10]. Using the carbon clearance test, they have found that phagocytic indexes are variable according to polysaccharide concentrations, and increase at 40 and $60 \mu \mathrm{g} / \mathrm{ml}$.

\section{Discussion}

Mousavi et al. [4] found that co-administration of Chenopodium album and $\mathrm{CpG}$ oligonucleotides extract reverses IgG2a/IgG1 ratios and increases IFN- $\gamma$ and IL-10 production in the murine model of asthma; these components can be used with other allergens in order to prevent inflammatory conditions. Another study indicated that water-soluble components from Alternanthera tenella are able to modulate effectively the immunological interactions [13].

Nose et al. [14] investigated the effects of crude polysaccharide fractions obtained from the shoot and hairy root of Glycyrrhizae sp. on the murine peritoneal macrophage function, in order to clarify whether plants grown under aseptic conditions produce immunomodulatory polysaccharides. Their results indicated that all crude polysaccharide fractions induced nitric oxide production by murine peritoneal macrophages in vitro and suggested that shoot and hairy root have biosynthesized polysaccharides that could have stimulated macrophages de novo. In other studies, crude polysaccharides from Plantago lanceolata, Rudbeckia fulgida, Salvia officinalis and Valeriana officinalis exhibited similar significant immunomodulatory activities using in vitro mitogenic and comitogenic rat thymocyte tests, with a particularly high adjuvant activity in the case of the Rudbeckia and Salvia polysaccharides $[15,16]$. The pectic polysacchariderich complex from Valeriana and Opilia celtidifola also stimulated the immune function of bone marrow cells and macrophage activity $[15,17]$. Polysaccharides fraction isolated from Ginkgo biloba folium has a good immunomodulatory activity rate [18], while fraction $\mathrm{C}$ from Caltha palustris extract can change the percentage and absolute number of $\mathrm{T}$ cell subsets in thymus, and $\mathrm{T}$ and $\mathrm{B}$ lymphocytes in the spleen and mesenteric lymph nodes [19].

Results of immunological assays have shown that the alkaline soluble polysaccharides of Ganoderma lucidum do not have any noticeable effect on monocyte phagocytosis and immune organ (spleen, thymus) weight of immunocompromised mice at the tested dosages [20]. Both in vitro and in vivo studies of $\mathrm{Xu}$ et al. [21] suggested that anti-tumor activities of Ganoderma lucidum polysaccharides are mediated by their immunomodulatory, anti-angiogenic, and cytotoxic effects. Ganoderma lucidum polysaccharides affect immune cells and immune-related cells including B lymphocytes, T lymphocytes, dendritic cells, macrophages, and natural killer cells. Although polysaccharides from many Chinese medicine herbs have been indicated to have immunomodulatory and anti-tumor activities [22-24], their immunoregulatory mechanisms are still not fully understood.

In conclusion, in this study we assessed in vitro the immunomodulatory effect of Chenopodium bonus-henricus polysaccharides on murine resident peritoneal macrophage cultures. The results showed an increase of phagocytic activities (phagocytic index and mean phagocytosis) due to polysaccharide treatments. For a better immunomodulatory effect, our study indicated a $30 \mu \mathrm{g} / \mathrm{ml}$ concentration of the polysaccharide extract from Chenopodium bonus-henricus.

The authors declare that they have no conflict of interest concerning this article.

\section{References}

1. Kokanova-Nedialkova Z, Nedialkov PT, Nikolov SD (2009): The genus chenopodium: Phytochemistry, ethnopharmacology and pharmacology. Phcon Rev 3: 280-306.

2. Grozeva N (2011): Chenopodium bonus henricus L. (Perennial goosefoot) in Bulgaria: II. Morphology, chorology and ecology. Trakia J Sci 9: 8-12.

3. Dubei N, Hanganu D, Olah NK (2004): Cercetarea calitativă şi cantitativă a polizaharidelor din Chenopodium bonus henricus L. Clujul Medical LXXVII (3): 592-596.

4. Mousavi T, Salek Moghadam A, Falak R, Tebyanian M (2008): Coadministration of $\mathrm{CpG}$ oligonucleotides and Chenopodium album extract reverse IgG2a/IgG1 ratios and increase IFN-gamma and IL-10 production in a murine model of asthama. Iran J Allergy Asthma Immunol 7: 1-6.

5. Siwicki AK, Skopińska-Różewska E, Hartwich M, et al. (2007): The influence of Rhodiola rosea extracts on non-specific and specific cellular immunity in pigs, rats and mice. Centr Eur J Immunol 32: 84-91.

6. Wójcik R, Siwicki AK, Skopińska-Różewska E, et al. (2008): The in vitro influence of Rhodiola quadrifida extracts on nonspecific cellular immunity in pigs. Centr Eur J Immunol 33: 193-196.

7. Brudaşcă GhF, Spînu M, Şandru CD, et al. (2008): Novel data on effects and biological activities of certain vegetal extracts. Clujul Med Vet 14: 40-52.

8. Şandru CD, Spînu M, Brudaşcă GhF, et al. (2008): Vegetal immunomodulators. Clujul Med Vet 14: 31-39.

9. Hanganu D, Mărculescu A, Olah N, et al. (2007): Chenopodium bonus henricus L. (Chenopodiaceae) a traditional plant used in Romania. Proc 6th European Colloquium on Ethnopharmacology, Leipzig; 49. 
10. Hanganu D, Dorhoi A, Pintea A, et al. (2010): Regulation of cellular-mediated immunity by Chenopodi boni henrici herba polysaccharides in hens. Rev Med Chir Soc Med Nat Iaşi 114: 587-592.

11. Miclea I, Zăhan M, Bunea A, Miclea V (2007): The isolation, analysis and testing of seabuckthorn carotenoids on murine macrophage cultures. Scientific papers. Anim Sci Biotech 40: 140-145.

12. Dorhoi A, Dobrean V, Zăhan M, Virag P (2006): Modulatory effects of several herbal extracts on avian peripheral blood cell immune responses. Phytother Res 20: 352-358.

13. Guerra RN, Pereira HA, Silveira LM, Olea RS (2003): Immunomodulatory properties of Alternanthera tenella Colla aqueous extracts in mice. Braz J Med Biol Res 36: 1215-1219.

14. Nose M, Terawaki K, Oguri K, et al. (1998): Activation of macrophages by crude polysaccharide fractions obtained from shoots of Glycyrrhiza glabra and hairy roots of Glycyrrhiza uralensis in vitro. Biol Pharm Bull 21: 1110-1112.

15. Ebringerová $\mathrm{A}$, Kardosová $\mathrm{A}$, Hromádková Z, Hríbalová $\mathrm{V}$ (2003): Mitogenic and comitogenic activities of polysaccharides from some European herbaceous plants. Fitoterapia 74: 52-61.

16. Capek P, Hríbalová V, Svandová E, et al. (2003): Characterization of immunomodulatory polysaccharides from Salvia officinalis L. Int J Biol Macromol 33: 113-119.

17. Togola A, Inngjerdingen M, Diallo D, et al. (2008): Polysaccharides with complement fixing and macrophage stimulation activity from Opilia celtidifolia, isolation and partial characterization. J Ethnopharmacol 115: 423-431.

18. Hăncianu M, Pavelescuz M, Miron A, et al. (2007): Polysaccharides fraction isolated from ginkgo biloba folium: immunopharmacological properties. Rev Med Chir Soc Med Nat Iaşi 111: 1070-1073.

19. Suszko A, Szczypka M, Lis M, et al. (2012): Influence of polysaccharide fraction $\mathrm{C}$ isolated from Caltha palustris L. on $\mathrm{T}$ and B lymphocyte subsets in mice. Centr Eur J Immunol 37: 193-199.

20. Huang SQ, Li JW, Wang Z, et al. (2010): Optimization of alkaline extraction of polysaccharides from Ganoderma lucidum and their effect on immune function in mice. Molecules 15: 3694-3708.

21. Xu Z, Chen X, Zhong Z, et al. (2011): Ganoderma lucidum polysaccharides: immunomodulation and potential anti-tumor activities. Am J Chin Med 39: 15-27.

22. Wong CK, Leung KN, Fung KP, Choy YM (1994): Immunomodulatory and anti-tumour polysaccharides from medicinal plants. J Int Med Res 22: 299-312.

23. Chang R (2002): Bioactive polysaccharides from traditional Chinese medicine herbs as anticancer adjuvants. J Altern Complement Med 8: 559-565.

24. Jiang MH, Zhu L, Jiang JG (2010): Immunoregulatory actions of polysaccharides from Chinese herbal medicine. Expert Opin Ther Targets 14: 1367-1402. 